\title{
MAPEAMENTO DA PRECIPITAÇÃO NO ESTADO DE ALAGOAS POR MEIO DE TÉCNICAS GEOESTATÍSTICAS
}

\section{RAINFALL MAPPING IN THE STATE OF ALAGOAS BY GEOSTATISTICAL TECHNIQUES}

\author{
Hugo Silva Comisso ${ }^{1}$ \\ Elias Silva de Medeiros $^{2}$
}

Resumo: O objetivo desta pesquisa consistiu em estudar a dinâmica espacial da precipitação no Estado de Alagoas, localizado no Nordeste do Brasil. Para responder ao objetivo da pesquisa foram empregadas técnicas geoestatísticas para construção de mapas de chuvas. Os resultados encontrados nesta pesquisa evidenciam uma grande variabilidade na distribuição das chuvas. O Leste Alagoano é o que possui maior precipitação acumulada, enquanto no Sertão as chuvas são escassas. Os resultados obtidos neste estudo podem auxiliar os órgãos responsáveis pelo gerenciamento dos recursos hídricos na tomada de decisão e na prevenção de desastres ambientais causados pelo excesso ou pela escassez das chuvas.

Palavras-chave: Krigagem Universal. Chuvas. Nordeste. Software R.

Abstract: The goal of this research was to study the spatial dynamics of precipitation in the State of Alagoas, located in the Northeast of Brazil. To answer the aim of the research, geostatistical techniques were employed for the construction of rain maps. The results found in this research evidenced a great variability of rainfalls distribution. The East of Alagoas has the greatest accumulated precipitation, whereas in Hinterland, the rainfalls are scarce. The results obtained in this study can help the agencies responsible for the management of water resources in decision making and in preventing environmental disasters caused by the excess or the scarcity of rainfalls.

Key words: Universal Kriging. Rainfall. Northeast. Software R.

Data de submissão: 18.01 .2021

Data de aprovação: 06.07.2021

Identificação e disponibilidade:

(https://revista.univap.br/index.php/revistaunivap/article/view/2580,

http://dx.doi.org/10.18066/revistaunivap.v27i55.2580).

\section{INTRODUÇÃO}

O conhecimento das estimativas da precipitação é de extrema importância para o gerenciamento dos recursos hídricos e para a compreensão do ciclo natural da água. Além disso, a precipitação é uma das variáveis meteorológicas de maior importância no setor hidrológico, influenciando diretamente as atividades humanas, tais como o cultivo agrícola, a pesca, a pecuária e, principalmente, no consumo humano e animal

1 Graduando em Engenharia Mecânica, Universidade Federal da Grande Dourados, E-mail: hugo comisso@hotmail.com.

2 Docente e Pesquisador em Estatística, Universidade Federal da Grande Dourados, E-mail: eliasestatistica@gmail.com. 
(PEREIRA et al., 2012).

Os valores observados da precipitação são fornecidos apenas para locais que dispõem de estações pluviométricas. Assim, para obtenção destas estimativas em locais que não dispõem destes aparelhos para amostragem, tem-se a necessidade de empregar métodos estatísticos de interpolação que levem em consideração a dependência espacial entre os locais amostrados (MEDEIROS et al., 2019). Neste contexto, a geoestatística é uma área da estatística espacial que tem sido amplamente utilizada para modelar a variabilidade de um fenômeno, levando em consideração a dependência espacial entre as observações (HUIJBREGTS, 1975; ISAAKS; SRIVASTAVA, 1989; JOURNEL, 1989).

Diversos trabalhos têm analisado e modelado a distribuição espacial da precipitação em regiões do Nordeste Brasileiro (NEB), criando mapas de interpolação baseadas em técnicas geoestatística, em especial, os métodos de krigagem. Lundgren, Sousa e Lundgren (2017) modelaram a distribuição espacial das chuvas mensais do Estado de Sergipe, utilizando de 64 estações meteorológicas irregularmente distribuídas em todo o estado e de técnicas de krigagem e cokrigagem. Medeiros e Olinda (2018) utilizando de técnicas de geoestatística analisaram a distribuição espacial das chuvas no Estado da Paraíba, que também possui um clima caracterizado pela irregularidade espacial e temporal da precipitação. Pereira et al. (2012) modelaram a variabilidade espacial da quantidade de dias de chuvas em 32 estações pluviométricas, localizados no Estado de Alagoas, o qual apresenta uma alta variabilidade espacial da precipitação em toda a região. Nessa perspectiva, convém mencionar que os aspectos climáticos análogos entre os estados da NEB corroboram para a realização de estudos a fim de investigar os níveis de chuvas em determinados períodos do ano.

O Estado de Alagoas, situado na NEB, é o segundo menor estado brasileiro, em dimensões territoriais, e corresponde a $0,33 \%$ do tamanho territorial do Brasil, e 1,79\% da região NEB. O estado se divide em três mesorregiões: Leste Alagoano, Agreste Alagoano e o Sertão Alagoano (IBGE, 2020). Em relação ao clima, o Estado de Alagoas apresenta uma alta variabilidade espacial entre as três mesorregiões. As temperaturas médias anuais variam de $22^{\circ} \mathrm{C}$ a $26^{\circ} \mathrm{C}$, exceto em algumas áreas serranas. O seu clima pode também se caracterizar, quanto a precipitação, pela irregularidade da distribuição das chuvas, resultando em desastres naturais ocasionados por processos ou fenômenos hidrometeorológicos, tais como inundações, enchentes e secas (CEPED, 2013).

Diante disto, o objetivo desta pesquisa consistiu em estudar a dinâmica espacial da precipitação no Estado de Alagoas, identificando áreas prioritárias para atuação dos órgãos responsáveis pelo gerenciamento dos recursos hídricos desta região.

\section{METODOLOGIA}

Situado na região NEB, o Estado de Alagoas tem uma área aproximada de $27.767 \mathrm{~km}^{2}$, correspondendo a cerca de $0,33 \%$ do território nacional. Com base na classificação de Köppen (ALVARES et al., 2013), toda a metade oriental no Estado de Alagoas, possui clima tropical e quente, com precipitação média entre $1000 \mathrm{~mm}$ e $1500 \mathrm{~mm}$, no período de outono/inverno. Presente em parte do Leste Alagoano, próximo à divisa do estado de Pernambuco o clima tropical com chuvas de outono e inverno, apresenta médias pluviométricas anuais entre $1500 \mathrm{~mm}$ e $2000 \mathrm{~mm}$. Nas mesorregiões do Agreste e do Sertão, apresentam-se condições semiáridas, com clima seco e quente, com uma precipitação pluviométrica média anual no Agreste de 
600 a 900 mm e no Sertão entre 400 mm e 600 mm (BARROS et al., 2012).

Na Figura 1 é apresentado o mapa do Estado de Alagoas com a identificação das 64 estações pluviométricas utilizadas neste estudo.

Figura 1 - Mapa do Estado de Alagoas com as identificações das mesorregiões e das estações pluviométricas utilizadas na pesquisa.

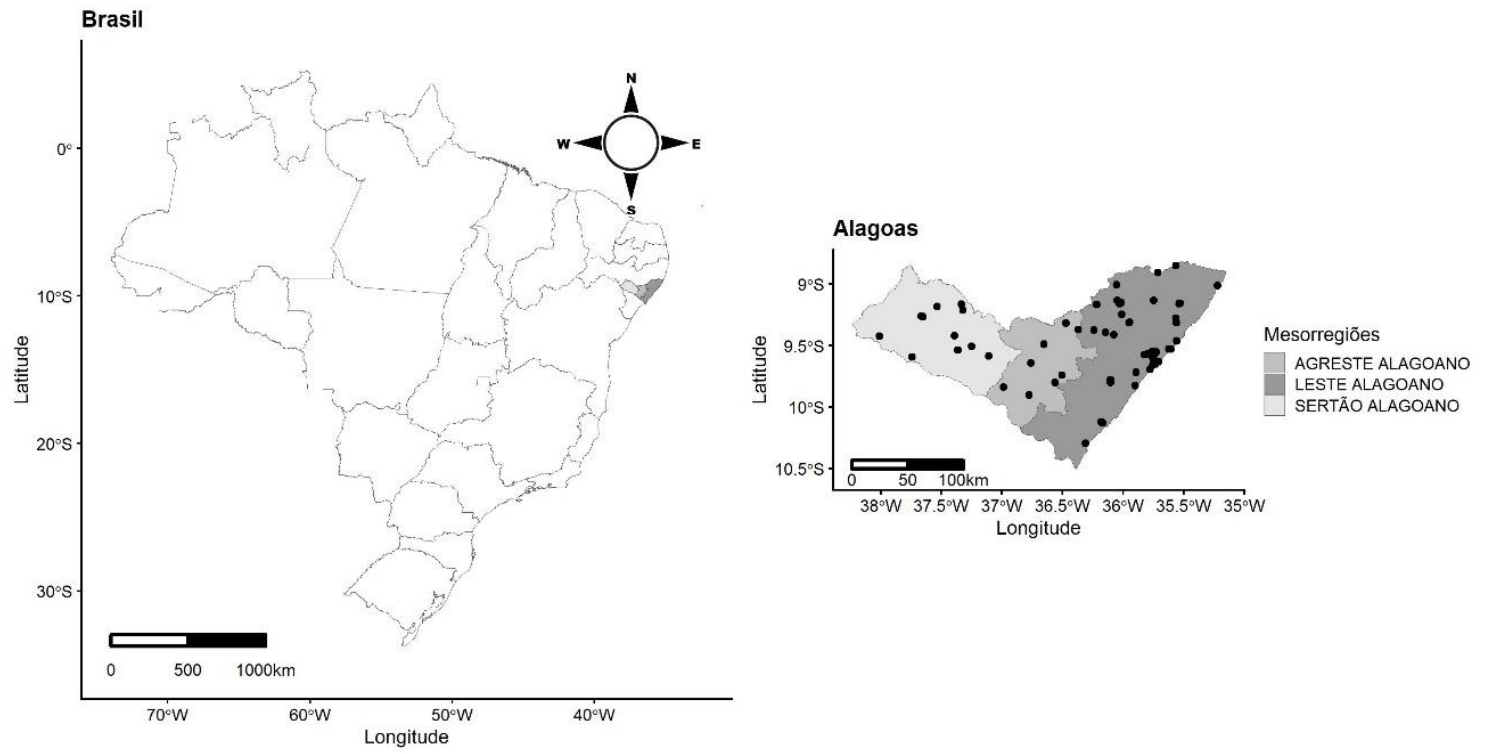

Fonte: Elaborado pelos autores (2021).

O conjunto de dados utilizado nesta pesquisa foi obtido por meio do Centro nacional de Monitoramento e Alertas de Desastres Naturais (http://www.cemaden.gov.br/). Para modelagem espacial considerou os valores médios da precipitação acumulada mensal com base no período de cinco anos (20162020). Na Figura 1 também é possível identificar a separação geográfica das mesorregiões que compõem o Estado de Alagoas.

Para uma análise exploratória da precipitação acumulada mensal, foram construídos gráficos de Box-Plot para cada um dos doze meses do ano, sendo possível investigar a variabilidade das chuvas dentro e entre os meses. Adicionalmente, de acordo com o regime pluviométrico, os meses foram divididos em dois grupos, período chuvoso e período seco.

Para modelagem da tendência da precipitação utilizou-se da regressão linear múltipla, sendo inseridas as próprias coordenadas geográficas (latitude e longitude) como covariáveis. Os efeitos lineares da latitude, longitude e o quadrático da longitude foram inseridos no modelo de regressão. Para seleção do modelo foi utilizado o algoritmo stepwise por meio do procedimento backward e como critério de seleção a estatística AIC (GONG; MATTEVADA; O'BRYANT, 2014).

Após removida a tendência, os resíduos foram submetidos a uma análise variográfica. Aos pseudo-dados do variograma amostral foram sugeridos os ajustes dos modelos teóricos de variograma Esférico, Exponencial e Gaussiano. O método dos mínimos quadrados ponderados foi utilizado para obtenção das estimativas dos parâmetros em cada modelo, sendo considerado como peso a quantidade de pontos $N(h)$ separados por uma distância $h,\left(N(h) / h^{2}\right)$.

Para interpolação da precipitação pluviométrica aplicou-se o método da Krigagem Universal (KU). Na KU o componente de tendência pode ser considerado 
como uma regressão múltipla, utilizando como variáveis regressoras as próprias coordenadas geográficas (BHATTACHARJEE; GHOSH; CHEN, 2019). O valor interpolado da precipitação $(\widehat{\boldsymbol{Z}})$ para um dado ponto $\left(\boldsymbol{x}_{\mathbf{0}}\right)$ é dado pela seguinte equação:

$$
\widehat{Z}\left(x_{0}\right)=\sum_{i=1}^{N} \lambda_{i} f_{k}\left(x_{i}\right)
$$

Na Equação (1), $\boldsymbol{N}$ corresponde a quantidade de estações pluviométricas que foram amostradas $(i=1,2, \ldots, 64), f_{k}(x)$ são funções conhecidas envolvendo as coordenadas geográficas e $\boldsymbol{k}$ é a quantidade de parâmetros presentes no componente de tendência. Para obtenção dos pesos, $\lambda_{i}$, tem a necessidade de uma resolução de um sistema de equações lineares dado por: $\boldsymbol{A} \boldsymbol{\lambda}=\boldsymbol{b}$. Para construção da matriz $\boldsymbol{A}$ e dos vetores $\lambda$ e $\boldsymbol{b}$ utilizam-se as funções das posições geográficas dos dados e do valor a ser interpolado (WEBSTER; OLIVER, 2007):

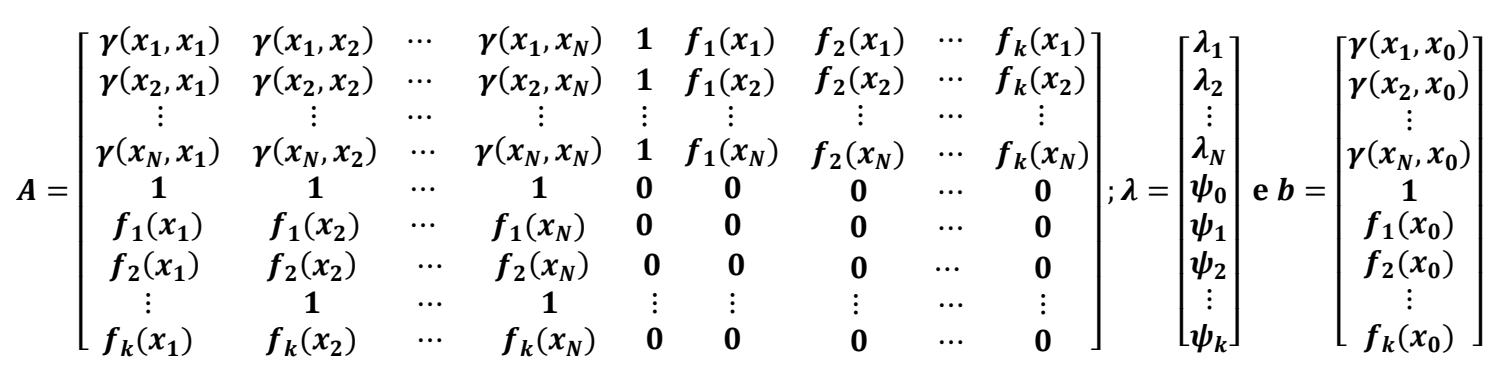

No sistema de equações lineares os valores $\lambda\left(\boldsymbol{x}_{\boldsymbol{i}}, \boldsymbol{x}_{\boldsymbol{j}}\right)$ são as semivariâncias dos resíduos entre os pontos amostrados $\boldsymbol{x}_{\boldsymbol{i}}$ e $\boldsymbol{x}_{\boldsymbol{j}}$, e $\boldsymbol{\lambda}\left(\boldsymbol{x}_{\boldsymbol{i}}, \boldsymbol{x}_{\mathbf{0}}\right)$ são as semivariâncias entre os pontos interpolados e os amostrados. Os pesos $\lambda_{i}$ são então inseridos na Equação (1), podendo assim ser obtidos os valores interpolados da precipitação pluviométrica. A variância da krigagem é dada por:

$$
\sigma_{K U}^{2}=b^{T} \lambda
$$

A seleção do modelo teórico de variograma deu-se por meio da validação cruzada "leave-one-out" durante a KU. Na validação cruzada foram obtidas a RaizQuadrada do Erro Quadrático Médio (RMSE), Viés Percentual (PBIAS) e o coeficiente de determinação $\left(R^{2}\right)$. Para seleção buscou-se os menores valores das estatísticas RMSE e PBIAS e os maiores valores de $\mathrm{R}^{2}$ (MORIASI et al., 2007). Com o modelo de variograma selecionado e obtidas suas estimativas, o passo final foi a interpolação dos valores da precipitação pluviométrica.

As análises estatísticas foram realizadas no software R (R CORE TEAM, 2020), o qual é um programa computacional livre e de código aberto. Por meio deste programa foram utilizados os pacotes ggplot2 (WICKHAM, 2016) e gstat (PEBESMA, 2004).

\section{RESULTADOS E DISCUSSÕES}

Na Figura 2 são apresentados os gráficos de Boxplot para cada mês do ano. Os dados referem-se aos totais mensais das 64 estações pluviométricas localizadas no Estado de Alagoas. Além disso, são apresentados os gráficos para os períodos chuvoso e seco. 
Figura 2 - Box-plot da precipitação pluviométrica $(\mathrm{mm})$ no Estado de Alagoas nas 64 estações pluviométricas durante o período de cinco anos (2016 - 2020).

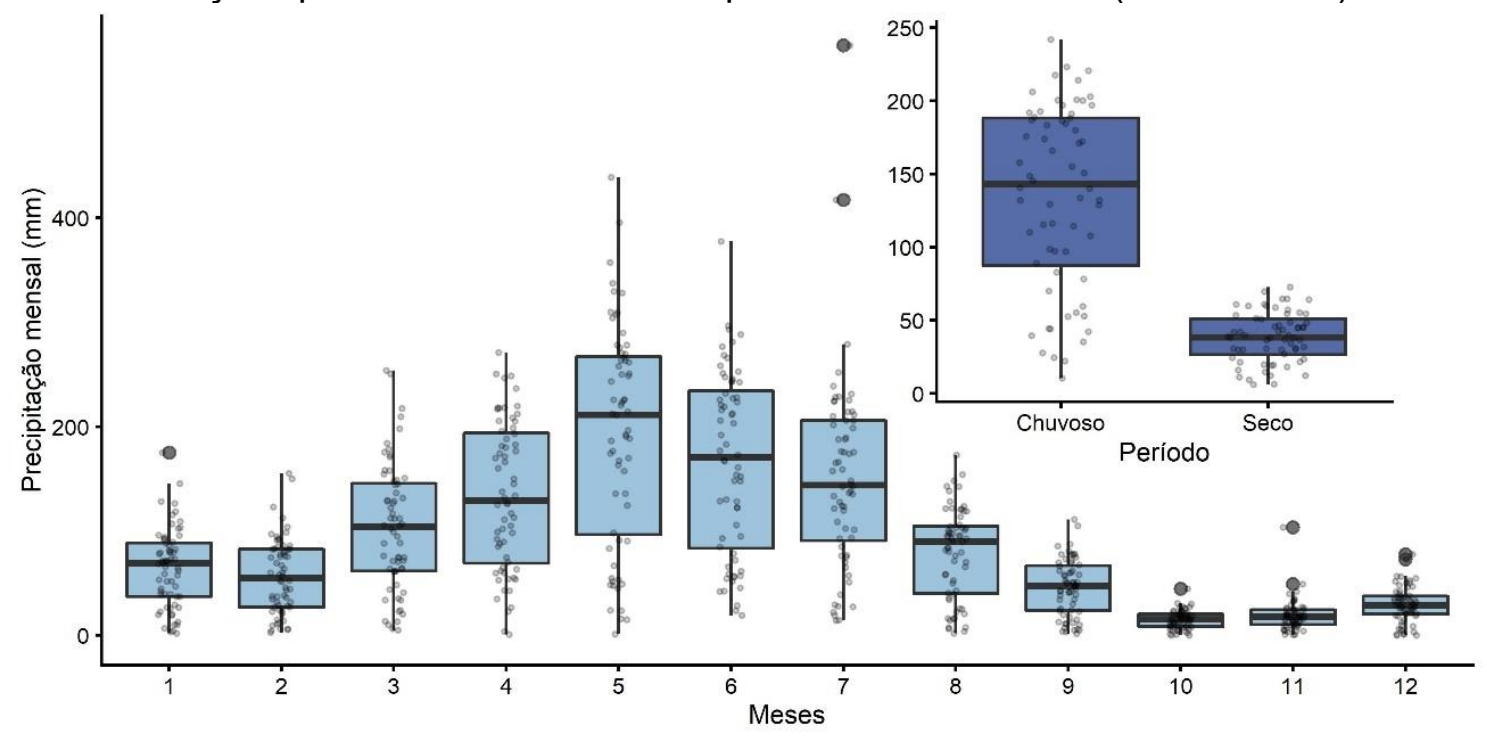

Fonte: Elaborado pelos autores (2021).

No mês de maio, $97,5 \%$ das observações apresentavam chuvas abaixo de 667 $\mathrm{mm}$, apresentando também os maiores índices de chuvas acumuladas para os quartis de $50 \%$ e $75 \%$. Em outubro, $75 \%$ das observações apresentaram chuvas inferiores a $24 \mathrm{~mm}$. Adicionalmente os meses de março a agosto, foram os que apresentaram maiores distribuições das chuvas e uma alta variabilidade, com base em 64 estações pluviométricas para o período de 2016 a 2020. Assim, considerou-se neste estudo o período chuvoso constituído pelos meses de março a agosto e os demais meses formando o período seco. O período chuvoso além de apresentar os maiores índices de precipitação pluviométrica também apresentou uma maior variabilidade.

De acordo com os estudos realizados sobre os registros de desastres naturais causados por enxurradas, no período de 1991 a 2012 (CEPED, 2013), verificou-se que no Estado de Alagoas, o mês de maio apresentou a segunda maior frequência de tal fenômeno no período em análise. Nesse mesmo estudo, foi possível observar a frequência mensal de todos os registros de inundações no Estado de Alagoas, registrando uma recorrência deste tipo de desastre entre os meses de maio a agosto. Além disso, durante o período chuvoso no estado de Alagoas ocorrem as maiores frequências dos valores máximos das chuvas, resultado do deslocamento anômalo da Zona de Convergência Intertropical (ZCIT) em direção ao Sul, ocasionando veranicos, período de estiagem, seguido de calor intenso (PEREIRA et al., 2012). Em especial, no mês de maio, mesmo sendo um período considerando chuvoso, tem-se a presença de longos períodos de estiagens, principalmente na mesorregião do Sertão Alagoano, ocasionando processos de desertificação, o qual tem agravado negativamente o desenvolvimento de culturas agrícolas e a pecuária nesta região. 
Figura 3 - Precipitação pluviométrica $(\mathrm{mm})$ nas 64 estações pluviométricas localizadas no Estado de Alagoas. Os valores são referentes a média de cinco anos (2016 - 2020). As diferentes cores representam os quantis (0 a $25 \%$; $25 \%$ a $50 \% ; 50 \%$ a $75 \% ; 75 \%$ a $100 \%$ ).

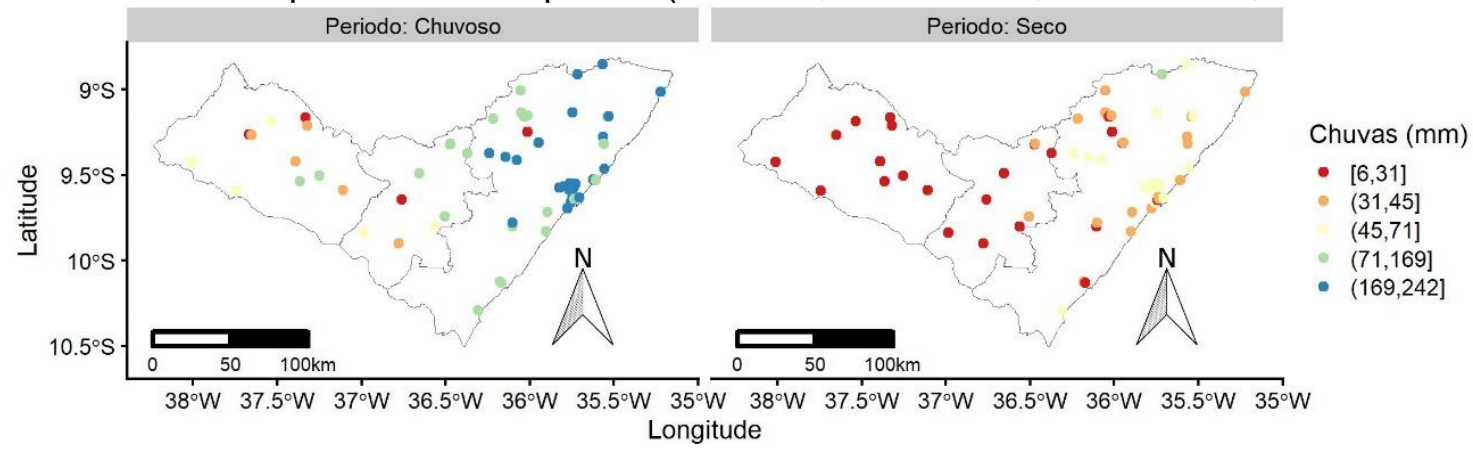

Fonte: Elaborado pelos autores (2021).

Na Figura 3 tem-se a precipitação pluviométrica nos períodos chuvoso e seco, com base na média calculada entre os anos de 2016 a 2020. A dependência espacial é uma característica específica à representação de dados através de subdivisões territoriais, que pode ser entendida como a tendência a que o valor de uma variável associada a uma determinada localização assemelhe-se mais ao valor de suas amostras vizinhas, do que basicamente ao restante das localizações do conjunto amostral. Pode-se observar que a mesorregião com maiores índices de precipitação é a do Leste Alagoano. A mesorregião do Sertão Alagoano apresenta um menor índice de precipitação, com um acumulado médio mensal inferior a $31 \mathrm{~mm}$ durante o período seco. Assim, a mesorregião do Leste Alagoano apresenta uma maior quantidade de chuvas, podendo chegar a até 8 vezes em comparação com a mesorregião do Sertão Alagoano. Santos et al. (2020) afirmam que as secas prolongadas no Sertão Alagoano potencializam os prejuízos no setor pecuário, causando diversos transtornos à sociedade, em especial, aos produtores e as famílias que residem nesta região. Além disso, nota-se uma alta variabilidade espacial da precipitação na direção Leste-Oeste.

Para a componente de tendência, foi selecionado o modelo contendo o intercepto e os efeitos linear e quadrático da longitude tanto no período chuvoso quanto no período seco. Por meio do coeficiente de determinação obtido pelo ajuste da tendência, tem-se que $68,5 \%$ e $43,1 \%$ da variabilidade da precipitação é explicada pela tendência nos períodos chuvoso e seco, respectivamente. Teixeira-Gandra, Damé e Simonete. (2015) utilizando do método de regressão múltipla, modelaram a tendência da precipitação mensal, sazonal e anual, em 26 estações localizadas no estado do Rio Grande do Sul, incorporando as coordenadas geográficas com covariáveis e atingindo um coeficiente de determinação de até $80 \%$ para a precipitação acumulada mensal. Em se tratando do estudo da distribuição das chuvas por meio de estações meteorológicas ou pluviométricas é comum a existência da dependência espacial das chuvas na região em análise, entretanto, os autores supracitados não investigaram a dependência espacial dos resíduos obtidos no ajuste da regressão múltipla. Wanderley, Amorim e Carvalho (2012) investigaram a distribuição espacial da precipitação pluviométrica mensal no mês de maio com base em 63 estações pluviométricas, no período de 1965 a 1980, no Estado de Alagoas. Entretanto, estes autores utilizaram a krigagem ordinária, não modelando a tendência da precipitação na região em estudo.

$\mathrm{Na}$ Tabela 1, tem-se os resultados da validação cruzada para os diferentes modelos teóricos nos períodos chuvoso e seco. 
Tabela 1 - Resultados da validação cruzada "leave-one-out" considerando os modelos teóricos de variograma Esférico, Exponencial e Gaussiano, seguindo das respectivas estatísticas Raiz Quadrado do Erro Quadrático Médio (RMSE), o percentual do viés (PBIAS) e o coeficiente de Determinação $\left(R^{2}\right)$.

\begin{tabular}{ccccccc}
\hline \multirow{2}{*}{ Modelo } & \multicolumn{3}{c}{ Período Chuvoso } & \multicolumn{3}{c}{ Período Seco } \\
\cline { 2 - 7 } & RMSE & PBIAS & $\mathbf{R}^{2}$ & RMSE & PBIAS & $\mathbf{R}^{\mathbf{2}}$ \\
\hline Esférico & $38,25 \mathrm{~mm}$ & $0,20 \%$ & $63,04 \%$ & $12,61 \mathrm{~mm}$ & $0,20 \%$ & $44,76 \%$ \\
Exponencial & $37,44 \mathrm{~mm}$ & $-0,10 \%$ & $64,47 \%$ & $12,48 \mathrm{~mm}$ & $0,00 \%$ & $45,90 \%$ \\
Gaussiano & $38,10 \mathrm{~mm}$ & $0,10 \%$ & $63,40 \%$ & $12,67 \mathrm{~mm}$ & $0,10 \%$ & $44,74 \%$ \\
\hline
\end{tabular}

Fonte: Elaborado pelos autores (2021).

O modelo Exponencial apresentou o menor valor da estatística RMSE e um maior valor de $\mathrm{R}^{2}$ nos períodos chuvoso e seco. No período seco foram encontrados os menores valores da RMSE, sugerindo que neste período tem-se menores erros de predição em relação ao período chuvoso. Medeiros, Lucio e Silva (2017) ao modelarem a precipitação acumulada anual no estado do Rio Grande do Norte, concluíram que o modelo Exponencial foi o mais adequado para ajuste à nuvem de pontos do variograma amostral. Entretanto, no trabalho destes autores supracitados a escolha do variograma ocorreu apenas de forma gráfica visual, não realizaram um procedimento estatístico como o da validação cruzada.

$\mathrm{Na}$ Figura 4, tem-se os ajustes dos variogramas amostrais seguido dos ajustes dos modelos Esférico, Exponencial e Gaussiano nos períodos chuvoso e seco.

Figura 4 - Variogramas amostrais (pontos em negrito) seguindo da linha de ajuste dos modelos teóricos sobre os resíduos, após removida a tendência da precipitação pluviométrica $(\mathrm{mm})$ nos períodos chuvoso e seco.

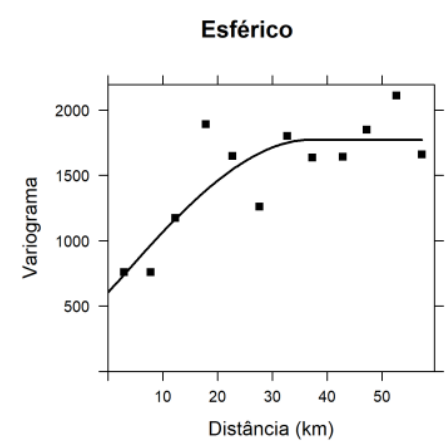

Esférico

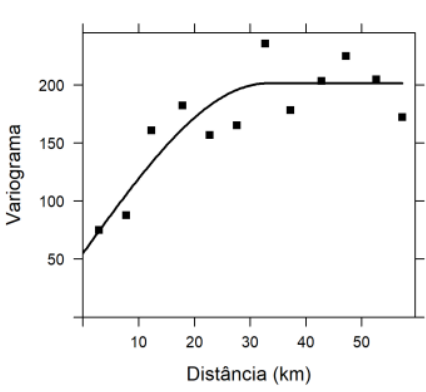

Periodo Chuvoso

Exponencial

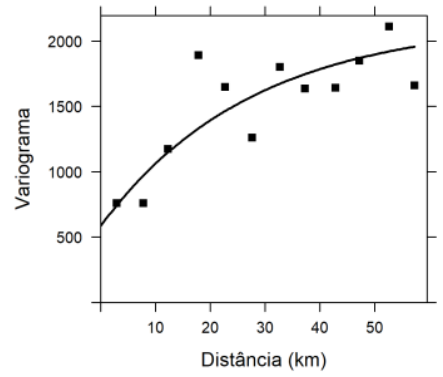

Periodo Seco

Exponencial

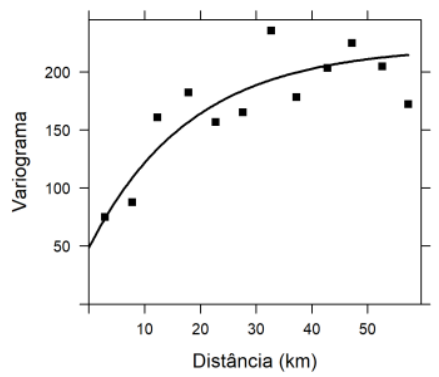

Gaussiano

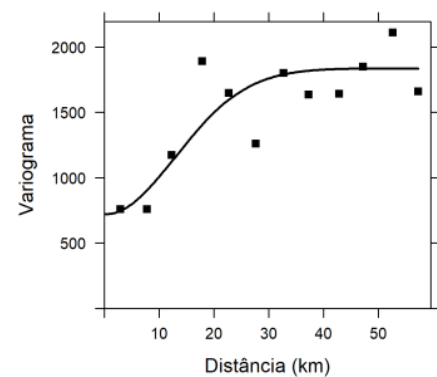

Gaussiano

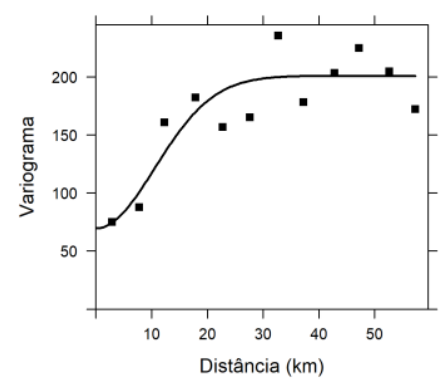

Fonte: Elaborado pelos autores (2021). 
$\mathrm{Na}$ Tabela 2 tem-se as estimativas do modelo Exponencial ajustado para os resíduos da precipitação pluviométrica nos períodos chuvoso e seco.

Tabela 2 - Estimativas dos modelos de variogramas selecionados pela validação cruzada "leave-one-out" para os períodos chuvoso e seco.

\begin{tabular}{ccccc}
\hline Período & Modelo & Pepita & Patamar & Alcance \\
\hline Chuvoso & Exponencial & 585,857 & 2153,087 & $27,64 \mathrm{~km}$ \\
Seco & Exponencial & 48,320 & 221,945 & $18,21 \mathrm{~km}$ \\
\hline
\end{tabular}

Fonte: Elaborado pelos autores (2021).

No modelo Exponencial, devido a presença de uma assíntota, quando a distância espacial tende a infinito o modelo converge para o efeito patamar, sendo utilizado como estimativa para o alcance espacial, em termos práticos, o triplo do alcance. Assim, neste estudo os alcances para os períodos chuvoso e seco foram de $82,92 \mathrm{~km}$ e $54,63 \mathrm{~km}$, respectivamente. Além disso, as estimativas de patamar sugerem uma menor variabilidade no período seco em relação ao período chuvoso, impactando no erro de predição nestes períodos. Wanderley, Amorim e Carvalho (2012) analisando a precipitação média mensal no mês de maio ajustaram um modelo esférico, obtendo um alcance de $72 \mathrm{~km}$, porém, os autores não removeram a tendência para construção e ajuste do modelo de variograma.

Na Figura 5 tem-se os mapas dos valores interpolados e o erro de predição da precipitação pluviométrica para os períodos chuvoso e seco no Estado de Alagoas. Conforme mencionado anteriormente, neste estudo para predição dos valores da precipitação, utilizou-se o método da Krigagem Universal, considerando longitude como uma covariável. Medeiros et al. (2017) realizaram um estudo comparando os diferentes métodos de krigagem às estimativas de mapas de chuvas anual em todo o Estado do Rio Grande do Norte, concluindo que os mapas baseados no método da Krigagem Universal apresentam menores erros de predição em comparação ao método da Krigagem Ordinária. 
Figura 5 - Krigagem da precipitação (lado esquerdo) e o erro da predição (lado direito) pluviométrica $(\mathrm{mm})$ nos períodos chuvoso e seco no Estado de Alagoas.
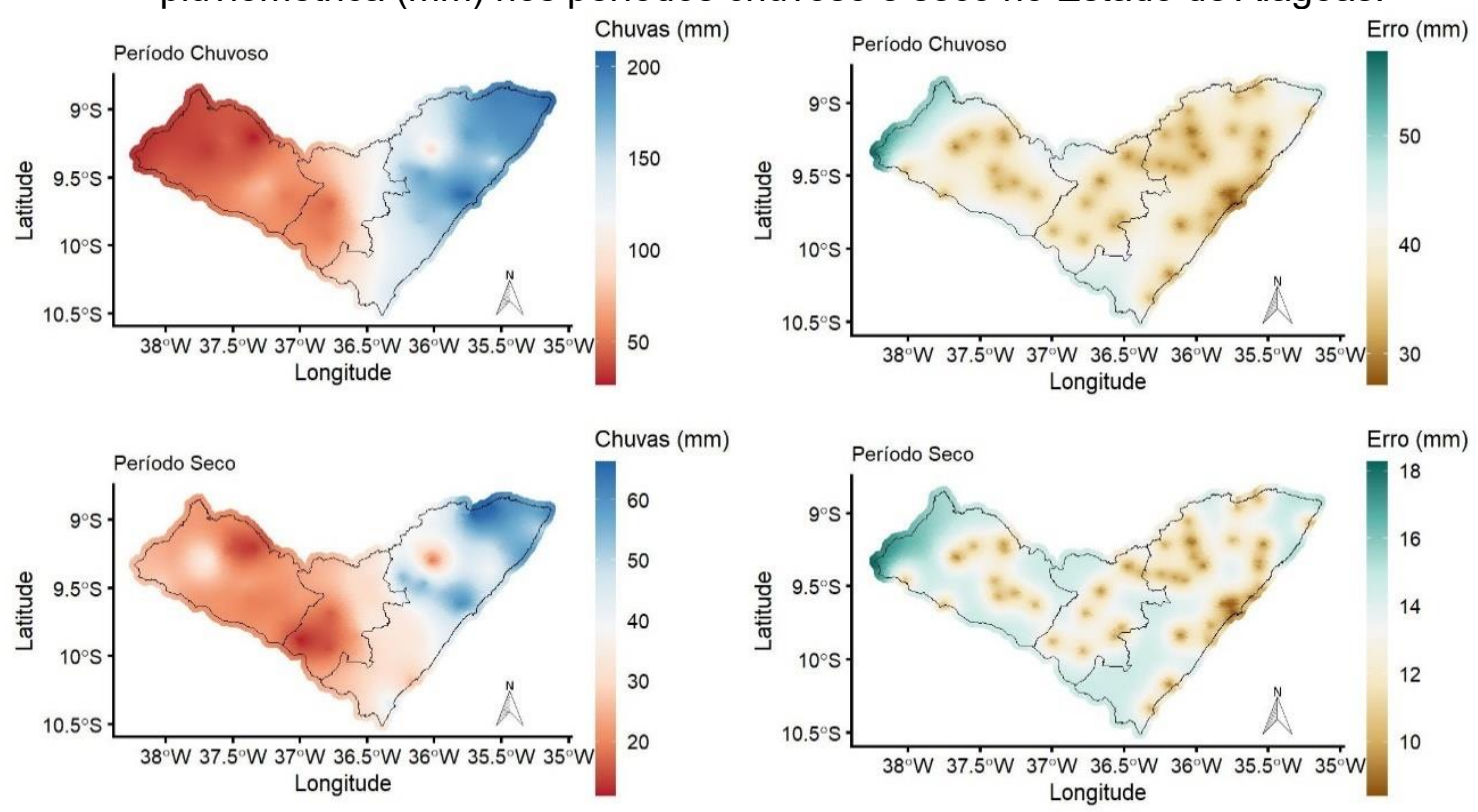

Fonte: Elaborado pelos autores (2021).

Na Figura 5 observa-se uma grande variabilidade da distribuição espacial da precipitação em ambos os períodos. Entretanto, o período seco apresentou os menores erros de predição. A mesorregião do Leste Alagoano é a que possui os maiores índices de chuva, em contrapartida, nota-se uma escassez da precipitação, principalmente, na mesorregião do Sertão Alagoano independente do período em análise. Além disso, na direção Norte-Sul de Alagoas, pode-se perceber uma baixa variabilidade da precipitação acumulada no período em estudo. Adicionalmente, todos os estados da região NEB apresentam uma alta variabilidade na distribuição das chuvas, com altos níveis em região próxima à costa litorânea, ocorrendo diminuição destes níveis ao deslocar em direção ao Sertão Nordestino, principalmente nas regiões que constituem o Semiárido Brasileiro.

Resultados semelhantes foram encontrados em Pereira et al. (2012), que investigaram a distribuição espacial das chuvas no Estado de Alagoas, concluindo que precipitação pluvial nesta região apresenta uma distribuição irregular entre as mesorregiões, sendo observado os maiores valores de número de dias chuvosos no Leste e no Agreste Alagoano. Estas características são explicadas pela influência dos fenômenos meteorológicos, em especial, La-Niña e El-Niño, que interferem na dinâmica da distribuição das chuvas em todo território nordestino (BARBOZA et al., 2019). Vale ressaltar que toda a mesorregião do Sertão Alagoano fica inserida na região do semiárido brasileiro, a qual é predominantemente caracterizada por períodos prolongados de estiagem, afetando diretamente a população, uma vez que é comum a prática da agricultura de subsistência (SANTOS et al., 2020).

\section{CONSIDERAÇÕES FINAIS}

Os resultados encontrados nesta pesquisa evidenciam uma grande variabilidade de chuvas, principalmente no período chuvoso no Estado de Alagoas. Nota-se uma tendência quadrática da precipitação neste estado na direção Leste-Oeste. Ao remover esta tendência, tem-se que o modelo Exponencial é o mais indicado para 
modelagem da variabilidade espacial das chuvas em Alagoas nos períodos chuvoso e seco.

A mesorregião do Leste Alagoano é a que possui maior precipitação acumulada, enquanto no Sertão as chuvas são escassas, independente do período. Espera-se que os resultados obtidos por meio desta pesquisa possam auxiliar os órgãos responsáveis pelo gerenciamento dos recursos hídricos na tomada de decisão e na prevenção de desastres ambientais causados pelo excesso e pela escassez das chuvas. Entretanto, para trabalhos futuros têm-se a necessidade de considerar na modelagem a dependência temporal das chuvas, sendo indicado a aplicação de um modelo geoestatístico espaço-temporal, auxiliando desta forma na construção de mapas com maiores poderes preditivos e o mais próximo possível da realidade.

\section{REFERÊNCIAS}

ALVARES, C. A. et al. Köppen's climate classification map for Brazil.

Meteorologische Zeitschrift, v. 22, n. 6, p. 711-728, 2013.

https://doi.org/10.1127/0941-2948/2013/0507.

BARBOZA, E. N. et al. Análise de precipitações pluviométricas entre 1974-2009 no município de Juazeiro do Norte, Ceará. Revista Brasileira de Gestão Ambiental, v. 13 , n. 4 , p. 20-26, 2019.

BARROS, A. H. C. et al. Climatologia do estado de Alagoas. Embrapa Solos. Recife: Embrapa Solos, 2012. 32 p. (Boletim de Pesquisa e Desenvolvimento, 211).

BHATTACHARJEE, S.; GHOSH, S. K.; CHEN, J. Semantic Kriging for Spatiotemporal Prediction. Singapore: Springer, 2019.

CEPED -CENTRO DE ESTUDOS E PESQUISAS EM ENGENHARIA E DEFESA CIVIL - UFSC. Atlas brasileiro de desastres naturais: 1991 a 2012.Florianópolis: Centro Universitário de Estudos e Pesquisas sobre Desastres, UFSC, 2013.

GONG, G.; MATTEVADA, S.; O'BRYANT, S. E. Comparison of the accuracy of kriging and IDW interpolations in estimating groundwater arsenic concentrations in Texas. Environmental Research, v. 130, p. 59-69, 2014.

https://doi.org/10.1016/j.envres.2013.12.005.

HUIJBREGTS, C. J. Regionalized variables and quantitative analysis of spatial data. In: DAVIS, J. C.; MCCULLAGH, M.J. (eds.). Display and Analysis of Spatial Data. John Wiley, New York, 1975. p. 38-53.

IBGE - INSTITUTO BRASILEIRO DE GEOGRAFIA E ESTATÍSTICA. Divisão Territorial Brasileira. 2020. Disponível em: https://www.ibge.gov.br/geociencias/organizacao-do-territorio/estruturaterritorial/23701-divisao-territorial-brasileira.html?=\&t=acesso-ao-produto. Acesso em: 9 out. 2020.

ISAAKS, E.H.; SRIVASTAVA, R.M. 1989. An introduction to applied geostatistics. New York: Oxford University Press, 1989. 561p. 
JOURNEL, A.G. Fundamentals of geostatistics in five lessons. Washington, DC: American Geophysical Union, 1989.40p. (Short Course in Geology, v. 8).

LUNDGREN, W. J. C.; SOUSA, I. D.; LUNDGREN, G. A. Estimativa pluviométrica através das técnicas da krigagem e cokrigagem no Estado de Sergipe. Revista Brasileira de Geografia Física, v. 10, n. 3, p. 854-865, 2017. https://doi.org/10.5935/1984-2295.20170055.

MEDEIROS, F. J.; LUCIO, P. S.; SILVA, H. J. F. Análise de Métodos de Krigagem na Estimativa da Precipitação no Estado do Rio Grande do Norte. Revista Brasileira de Geografia Física, v. 10, n. 5, p. 1668-1676, 2017. https://doi.org/10.26848/rbgf.v10.5.p1668-1676.

MEDEIROS, E. S.; OLINDA, R. A. Probability maps for the rainy quarter in the state of paraiba. Revista Univap, v. 25, n. 46, p. 19-29, 2018.

http://dx.doi.org/10.18066/revistaunivap.v24i46.1902.

MEDEIROS, E. S. et al. Modeling Spatiotemporal Rainfall Variability in Paraíba, Brazil. Water, v. 11, n. 9, p.1843, 2019. https://doi.org/10.3390/w11091843.

MORIASI, D. N. et al. Model evaluation guidelines for systematic quantification of accuracy in watershed simulations. Transactions of the ASABE, v. 50, n. 3, p. 885900, 2007. https://doi.org/10.13031/2013.23153.

PEBESMA, E. J. Multivariable geostatistics in S: the gstat package. Computers and geosciences, v. 30, n. 7, p. 683-691, 2004. https://doi.org/10.1016/j.cageo.2004.03.012.

PEREIRA, E. R. R. et al. Variabilidade do número de dias de chuva no estado de Alagoas. Applied Research and Agrotechnology, v. 5, n. 1, p. 7-26, 2012. https://doi.org/10.5777/paet.v5i1.1696.

R CORE TEAM. R: a language and environment for statistical computing. Version 3.6.0. Vienna, Austria: R Foundation for Statistical Computing, 2020.

SANTOS, M. A. A. et al. Diagnóstico do uso da água e do solo na pecuária no do Canal do Sertão de Alagoas. Brazilian Journal of Development, v. 6, n. 7, p. 52093-52107, 2020. https://doi.org/10.34117/bjdv6n7-745

TEIXEIRA-GANDRA, C. F. A.; DAMÉ, R. D. C. F.; SIMONETE, M. A. Predição da precipitação a partir das coordenadas geográficas no Estado do Rio Grande do Sul. Revista Brasileira de Geografia Física, v. 8, n. 3, p. 848-856, 2015. https://doi.org/10.5935/1984-2295.20150037

WANDERLEY, H. S.; AMORIM, R. F. C.; CARVALHO, F. O. D. Variabilidade espacial e preenchimento de falhas de dados pluviométricos para o estado de Alagoas.

Revista Brasileira de Meteorologia, v. 27, n. 3, p. 347-354, 2012. https://doi.org/10.1590/S0102-77862012000300009 
WEBSTER, R.; OLIVER, M. A. Geostatistics for environmental scientists. New York: John Wiley \& Sons, 2007.

WICKHAM, H. ggplot2: Elegant Graphics for Data Analysis. Cham, Switzerland: Springer International Publishing, 2016. 